\title{
Exposure to aflatoxin from groundnut among Senegalese adults
}

\author{
S. Watson ${ }^{1}$, J. Atehnkeng ${ }^{2}$, P. Madiallacké Diedhiou ${ }^{3}$, R. Bandyopadhyay ${ }^{2}$, C. Srey ${ }^{1}$, C. P. Wild ${ }^{4}$ \\ and Y. Y. Gong ${ }^{1}$ \\ ${ }^{1}$ Institute for Global Food Security, Queen's University Belfast, Belfast BT9 5HN, UK, ${ }^{2}$ International Institute of \\ Tropical Agriculture, Ibadan, Nigeria, ${ }^{3}$ University of Thies, Thies, Senegal and ${ }^{4}$ International Agency for Research on \\ Cancer (IARC), Lyon, France
}

Mycotoxins are naturally occurring secondary metabolites of molds that contaminate $25 \%$ of major food crops worldwide ${ }^{(1)}$. Aflatoxin the most potent mycotoxin has been associated with detrimental health outcomes namely: immunosuppression, impaired child growth, liver cancer ${ }^{(2)}$ and protein malnutrition ${ }^{(3)}$. Aflatoxin contamination is prevalent in warm humid climates and irrigated hot deserts. Groundnut a dietary staple and cash crop of Senegal is typically contaminated with aflatoxin. There is a paucity of information regarding aflatoxin exposure in Senegalese adults and if exposure levels vary across geographical boundaries and seasons (harvest and post-harvest). The aim of the study was to determine geographical and seasonal variations in aflatoxin dietary exposure levels in adults from Senegal.

A total of 168 adults $(50 \%$ male) were recruited from three districts, Nioro $(n=90)$, St Louis $(n=40)$ and Mboro $(n=38)$, across three agro-ecological zones in Senegal; Groundnut Basin (Nioro), a site of intensive rain fed groundnut production; Senegal Valley (St Louis) and Niayes (Mboro), both in north of the country were groundnut is produced under irrigated conditions. Aflatoxin dietary exposure was assessed using the aflatoxin-albumin adduct (AF-alb) biomarker measured by competitive ELISA, and household groundnut samples were assessed for total aflatoxin using the TLC method. Samples were collected during harvest and post-harvest to determine the impact of storage on aflatoxin contamination. Dietary information was collected via questionnaire at baseline (Nioro participants only).

Aflatoxin (ng/g) was detected in 78\%, 62\% and 67\% of harvest groundnut samples from Nioro, St Louis and Mboro respectively. During post-harvest aflatoxin was detected in $26 \%$ and $80 \%$ of groundnut samples from Nioro and St Louis. Post-harvest groundnut samples were not available to collect from Mboro as most of the groundnut had been sold at harvest.

As shown in the table above Nioro participants had higher AF-alb (pg/mg) levels at harvest compared to post-harvest; while, St Louis participants had higher AF-alb (pg/mg) at post-harvest compared to harvest. Across agro-ecological zones, Nioro had higher AF-alb (pg/mg) levels at harvest than St Louis and Mboro $(P<0 \cdot 001)$. Both Nioro and Mboro had higher AF-alb (pg/mg) levels than St Louis during post-harvest $(P<0.001)$. Similar trends were observed when assessing aflatoxin in household groundnut samples. Based on limited dietary information obtained in Nioro during the harvest time, Nioro participants reported consuming groundnuts on average 6.3 days a week and maize on average 4.2 days a week. Approximately, $71 \%$ and $44 \%$ of Nioro participants reported consuming groundnuts and maize daily.

Aflatoxin exposure is prevalent among Senegalese adults with Nioro having the highest exposure in the studied population, although seasonal pattern varied amongst the three districts. Variations in groundnut intake, different harvest and storage practices, and if groundnuts are grown under rainfed or irrigated conditions are thought to be possible explanations for these observations. Overall, the results from this study reinforce the need for interventions to reduce aflatoxin exposure, specifically, in high-risk areas. This in turn may positively impact health and prevent economic losses in Senegal.

\begin{tabular}{lcccccc}
\hline & \multicolumn{2}{l}{$\begin{array}{l}\text { Harvest AF-alb (pg/mg } \\
\text { albumin) }\end{array}$} & & \multicolumn{2}{l}{$\begin{array}{l}\text { Post-harvest AF-alb (pg/ } \\
\text { mg albumin) }\end{array}$} & \\
\cline { 2 - 3 } District & $\begin{array}{c}\text { Geometric } \\
\text { mean }\end{array}$ & $95 \%$ CI & & $\begin{array}{c}\text { Geometric } \\
\text { mean }\end{array}$ & $95 \%$ CI & \multirow{2}{*}{ P value } \\
\hline Nioro & $80 \cdot 0$ & $67 \cdot 4,95 \cdot 0$ & $58 \cdot 6$ & $51 \cdot 5,66 \cdot 7$ & $0 \cdot 026$ \\
St Louis & $15 \cdot 6$ & $12 \cdot 2,20 \cdot 0$ & & $25 \cdot 6$ & $17 \cdot 6,37 \cdot 2$ & $0 \cdot 032$ \\
Mboro & $33 \cdot 3$ & $28 \cdot 6,38 \cdot 8$ & & $42 \cdot 6$ & $30 \cdot 2,60 \cdot 1$ & $0 \cdot 087$ \\
\hline
\end{tabular}

AF-alb levels were logged transformed for analysis. ${ }^{1}$ Analysed using paired sample t-test.

1. Food and Agriculture Organization (2014): Mycotoxins. http://www.fao.org/food/food-safety-quality/a-z-index/mycotoxins/en/(accessed March 2014).

2. Wild CP \& Gong YY (2010) Carcinogenesis 31, 71-82.

3. Hatem NL, Hassab HM, Al-Rahman A et al. (2005) Food Nutr Bull 26, 49-56 